\title{
Screening two mutations in the dysferlin gene by exon capture and sequence analysis: A case report
}

\author{
XUEYAN WANG ${ }^{1,2}$, YUN YANG ${ }^{3}$ and RONG ZHOU ${ }^{1}$ \\ ${ }^{1}$ Department of Obstetrics and Gynecology, Huaxi Second Hospital of Sichuan University, Chengdu, Sichuan 610041; \\ ${ }^{2}$ Department of Prenatal Diagnosis, Women and Children's Hospital of Sichuan Province, \\ Chengdu, Sichuan 610000; ${ }^{3}$ BGI-Wuhan, Wuhan, Hubei 430000, P.R. China
}

Received June 6, 2015; Accepted January 19, 2016

DOI: $10.3892 /$ etm.2016.3332

\begin{abstract}
A patient with progressive muscular atrophy was assessed for the disease-associated genes by next-generation sequencing technology and exon trap and sequence analysis. The results of the investigation identified 399 genes, covering all exons in addition to $10 \mathrm{bp}$ on either side, which are specific to 659 types of neuromuscular disorders, including hypotypes. Exon capture and sequence analysis revealed that the patient possessed two splice site mutations in the dysferlin (DYSF) gene, c. $144+1 \mathrm{G}>\mathrm{A}$ and c. $342+1 \mathrm{G}>\mathrm{T}$, and the presence of the mutations was confirmed by Sanger sequencing. The patient's mother and sister were also assessed and confirmed to have mutations within the DYSF gene, the mother with c. $342+1 \mathrm{G}>\mathrm{T}$ and the sister with c.144+1G $>$ A. The two splice site mutations in the DYSF gene, c.144+1G $>$ A and c.342+1G $>$ T, have not previously been reported. Therefore, exon capture and sequence analysis is able to rapidly and efficiently screen for genetic alterations in neuromuscular disorders.
\end{abstract}

\section{Introduction}

The present study presents the case of a 41 year-old male patient admitted to the Department of Prenatal Diagnosis, Women \& Children's Hospital of Sichuan Province (Chengdu, China) in November 2012. The age of onset of the disease was 35 years, at which time the patient had difficulty in climbing stairs, fatigue, weakness and markedly elevated serum creatine kinase (level reached, $580 \mathrm{U} / \mathrm{l}$; normal level, 200U/1). An electromyogram (EMG) revealed myogenic damage. Thus, the patient was suspected to have progressive muscular dystrophy, and advised to undergo a muscle biopsy and an assessment to uncover the presence of any disease-associated genes. However, the patient declined both

Correspondence to: Dr Rong Zhou, Department of Obstetrics and Gynecology, Huaxi Second Hospital of Sichuan University, 20 The Third People's Road, Chengdu, Sichuan 610041 P.R. China E-mail: rong_zhou0512@163.com

Key words: mutations, dysferlin gene, next-generation sequencing options. In the following years, the patient experienced difficulty performing squats and washes, lacked strength to walk and his proximal muscle indicated atrophy, though the patient had no difficulty in swallowing. No similar cases had been reported in the patient's family. Due to pregnancy, the wife of the patient wished to know the impact of the disease on future generations and required a clear diagnosis. However, the patient refused a muscle biopsy and the consulting physician only examined the disease-associated genes of the patient and his family.

\section{Patients and methods}

Subjects. The research subjects in the present study included 4 individuals, the patient, whose father was no longer alive, and the patient's mother, sister and wife.

Gene fragment acquisition. Venous blood was obtained (5 ml) from each of the subjects. DNA was extracted according to standard protocol using a QIAamp DNA Blood Mini kit (Qiagen $\mathrm{GmbH}$, Hilden, Germany). Subsequently, DNA was degraded into fragments of 200-250 bp in length using a Covaris S2 device, (Covaris, Inc., Woburn, MA, USA) and purified using Ampure XP Beads (Beckman Coulter, Inc., Brea, CA, USA). Following the treatment of $1 \mu \mathrm{g}$ purified DNA fragments with terminal repair, and the addition of an 'A' by ligation reaction, a DNA library for each patient was created. The DNA library was combined with the gene microarray 'Human Sequence Capture 2.1 M Array' (Roche Applied Science, Madison, WI, USA) at $42^{\circ} \mathrm{C}$ for $72 \mathrm{~h}$. Following this, the gene microarray was washed and an elution reaction was performed, followed by an amplification step. Enrichment of the samples was assessed using an Agilent 2100 Bioanalyzer (Agilent Technologies, Inc., Santa Clara, CA, USA) and ABI StepOne (Thermo Fisher Scientific, Inc., Waltham, MA, USA). Finally, the samples were treated with continuous bi-directional sequencing for 90 cycles by an Illumina HiSeq 2000 sequencing system (Illumina, Inc., SanDiego, CA, USA) and the original sequencing data were revealed using Illumina Pipeline software (Illumina, Inc; version 1.3.4). A total of 399 genes were identified, covering all exons in addition to $10 \mathrm{bp}$ on either side, which were associated with 659 types of neuromuscular disorder, including hypotypes. 
Table I. Primer information validated by the Sanger method.

\begin{tabular}{lcl}
\hline Location & Primer & \multicolumn{1}{c}{ Sequence (5'-3') } \\
\hline c.144+1 G>A & F & TCTCACCATCGCACTCCAG \\
& R & GAAGGCACCTCCTCCACAA \\
c.342+1 G $>$ T & F & ATCTGAGTGGTGGCAGTGAG \\
& R & GCAGGAAGAACAACGGAGGA
\end{tabular}

F, forward; R, reverse.

Data analyses. The sequencing quality of raw reads were evaluated, in order to remove reads of low quality and those containing partial adapter sequences. Sequences were compared with Burrows Wheeler Aligner (BWA; Multi-Vision software package; version 0.7.12-r1039) and HG19 software (1). Concurrently, sequence capture was evaluated using SOAPsnp (version 1.03), SAOPindel (version 2.01) and Samtools software (version 0.1.18) (2,3). Initially, single nucleotide variants, insertion sand deletions were excluded using information from databases including NCBI dbSNP, HapMap, the 1,000 human genomes project dataset and a database of 100 Chinese healthy adults. Suspicious mutations were screened and non-pathogenic polymorphism sites were excluded, such as same sense mutations (4). The experimental protocol, data processing and analysis were completed with the assistance of the Beijing Genomics Institute (Beijing, China).

Validation by the Sanger method. Primers were designed both upstream and downstream for all the fragments the pathogenic point mutation was present in. The primers were subsequently amplified by polymerase chain reaction and products were sequenced with the Sanger method. The thermocycling conditions were as follows: First phase, $2 \mathrm{~min}$ at $94^{\circ} \mathrm{C}$, followed by the second phase, $15 \mathrm{sec}$ at $94^{\circ} \mathrm{C}, 30 \mathrm{sec}$ at $58^{\circ} \mathrm{C}$ and $30 \mathrm{sec}$ at $72^{\circ} \mathrm{C}$ for 14 cycles. The third phase was 5 min at $72^{\circ} \mathrm{C}$, followed by $4^{\circ} \mathrm{C}$. The results were compared with the standard gene sequence to validate the results of the microarray and high-throughput sequencing. Primer information for c.144+1G $>$ A and c. $342+1 G>T$ in the DYSF gene are displayed in Table I.

\section{Results}

Exon capture and sequence analysis revealed 54 point mutations in the DYSF gene. Only two splice site mutations were novel identifications, all others were also present in the general population. Once validated by the Sanger method, the results were consolidated by exon capture and sequence analysis. The patient possessed two splice site mutation in the DYSF gene, c. $144+1 \mathrm{G}>\mathrm{A}$ and c.342+1G $>\mathrm{T}$ (Fig. 1). The patient's mother and sister also had mutations, the heterozygotic DYSF c. $342+1 \mathrm{G}>\mathrm{T}$ splice site mutation was observed in the patient's mother, whereas the patient's sister had the c. $144+1 \mathrm{G}>\mathrm{A}$, DYST splice site mutation, also heterozygotic (Fig. 2). Thus, the patient's father may have been a carrier of the splice site mutation with c.144+1G $>$ A. In addition, the patient's wife did no carry the gene which can cause limb-girdle muscular dystrophy type 2B (LGMD2B) (Fig. 1).

\section{Discussion}

LGMD, also known as Erb's muscular dystrophy, is a genetically heterogeneous group of rare muscular dystrophies, which also display clinical diversity (5) LGMD predominantly affects the hip and shoulder muscles and is characterized by progressive muscle wasting (6). The LGMD type 1 family is autosomal dominant, whereas the LGMD type 2 family is autosomal recessive. LGMD2B arises due to mutations in the gene encoding DYSF, a skeletal muscle protein located on chromosome 2p12-14 (7). Bashir et al (8) previously described age at onset ranged from 15-25 years and patients typically present with fatigue, weakness, difficulty climbing stairs, and markedly elevated serum creatine kinase. The study also reported that EMG revealed myopathic changes, and skeletal muscle biopsies revealed severe myopathic changes, including variations in fiber size, fiber splitting, an increase in connective tissue in addition to sporadic necrotic changes (8). Disease progression was observed to be relatively slow. Amino acid sequence analysis of the DYSF protein has revealed 7 sites that correspond to caveolin-3 scaffold-binding motifs, and 1 site that is a potential target to bind the WW domain of the caveolin-3 protein .One function of dysferlinis is to interact with caveolin-3 to subserve signaling functions of caveolae (9). Therefore, DYSF may repair the damage to sarcolemma caused by muscle contraction, which is why LGMD2B patients may have slowly progressive muscular weakness of the lower limbs, beginning in the late second decade of life. This may explain the later age at onset of the 41 year-old male patient in the present study. The DYSF protein is encoded by the DYSF gene (10), which is associated with skeletal muscle repair (2). DYSF has predominantly been investigated for its role in a cellular process known as membrane repair (2). It has previously been revealed that, in patients with LGMD2B, the absence of DYSF prevents the repair of damage to the muscle fiber membrane (11).

Bashir et al (8) also reported that the virulence genes of LGMD2B were associated with two sites on the short arm of chromosome 2, D2S134 and D2S136, as revealed by linkage analysis, and also located pathogenic genes on chromosome 2p13-16 $(2,12,13)$. Passos-Bueno et al (10) further determined the location of DYSF to be on the short arm of chromosome 2 between D2S292 and D2S286 following the study of a Brazilian family. Furthermore, Bashir et al (12) located a virulence gene of LGMD2B between D2S2113 and D2S2112 in 1996 by haplotyping (14). The full length of the DYSF gene is $\sim 150 \mathrm{~kb}$ and consists of 55 exons and an open reading frame of $6243 \mathrm{bp}(15)$. The coding sequence (CDS) of the DYSF gene is in the 377-6712 interval of the mRNA sequence, encompassing 6336 bp $(16,17)$.

In the present study, when splice site mutation c.144+1G>A on exon 2 occurred, splice site GU moved 4 bases backward, leading to the insert size of ATAT following the 144th base of CDS, which resulted in an abnormal translation from 49th amino acids. In addition, when splice site mutations c. $342+1 \mathrm{G}>\mathrm{T}$ on exon 4 occurred, splice site GU moved 4 bases backward, leading to the insert size of ATAA to the position following the 342nd base of CDS, which resulted in an abnormal 


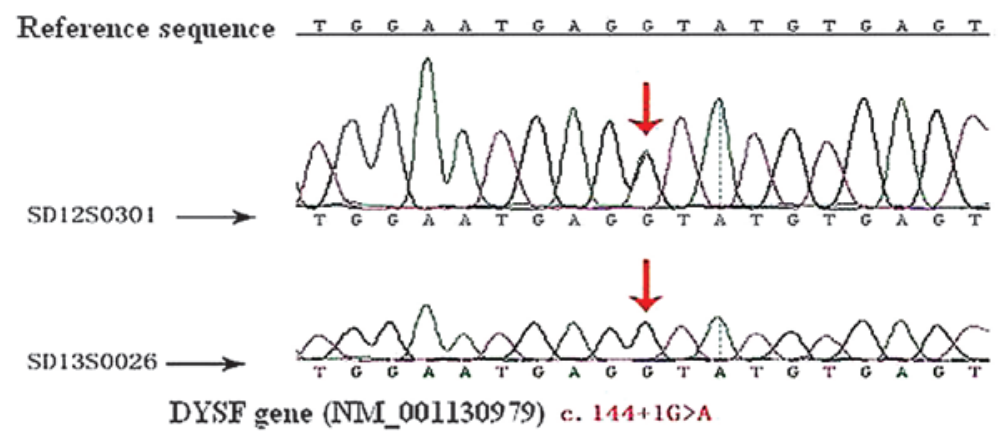

Reference sequence \begin{tabular}{lllllllllllllllllll}
$A$ & $C$ & $A$ & $G$ & $G$ & $G$ & $G$ & $T$ & $A$ & $A$ & $G$ & $T$ & $G$ & $C$ & $C$ & $C$ & $A$ & $T$ & $c$ \\
\hline
\end{tabular}

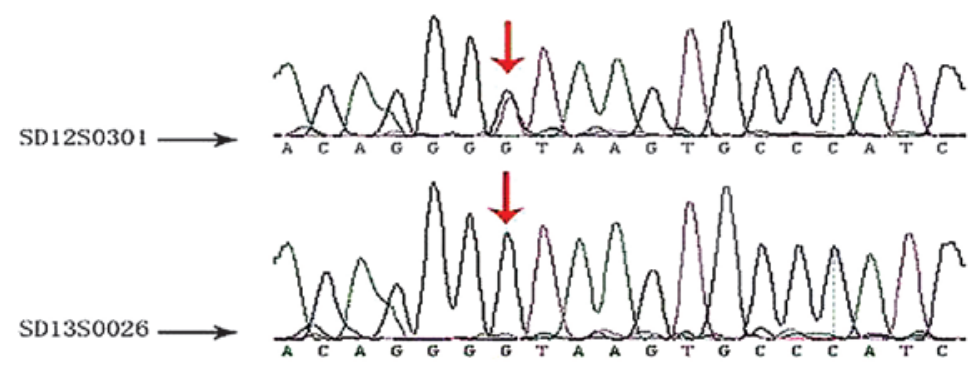

DYSF gene (NM_001130979) c. 312+1G>T

Figure 1. Sequence maps of the patient and the patient's wife by exon trapping and sequence analysis. SD13S0301, patient; SD13S0026. patient's wife. DYST, dysferlin.
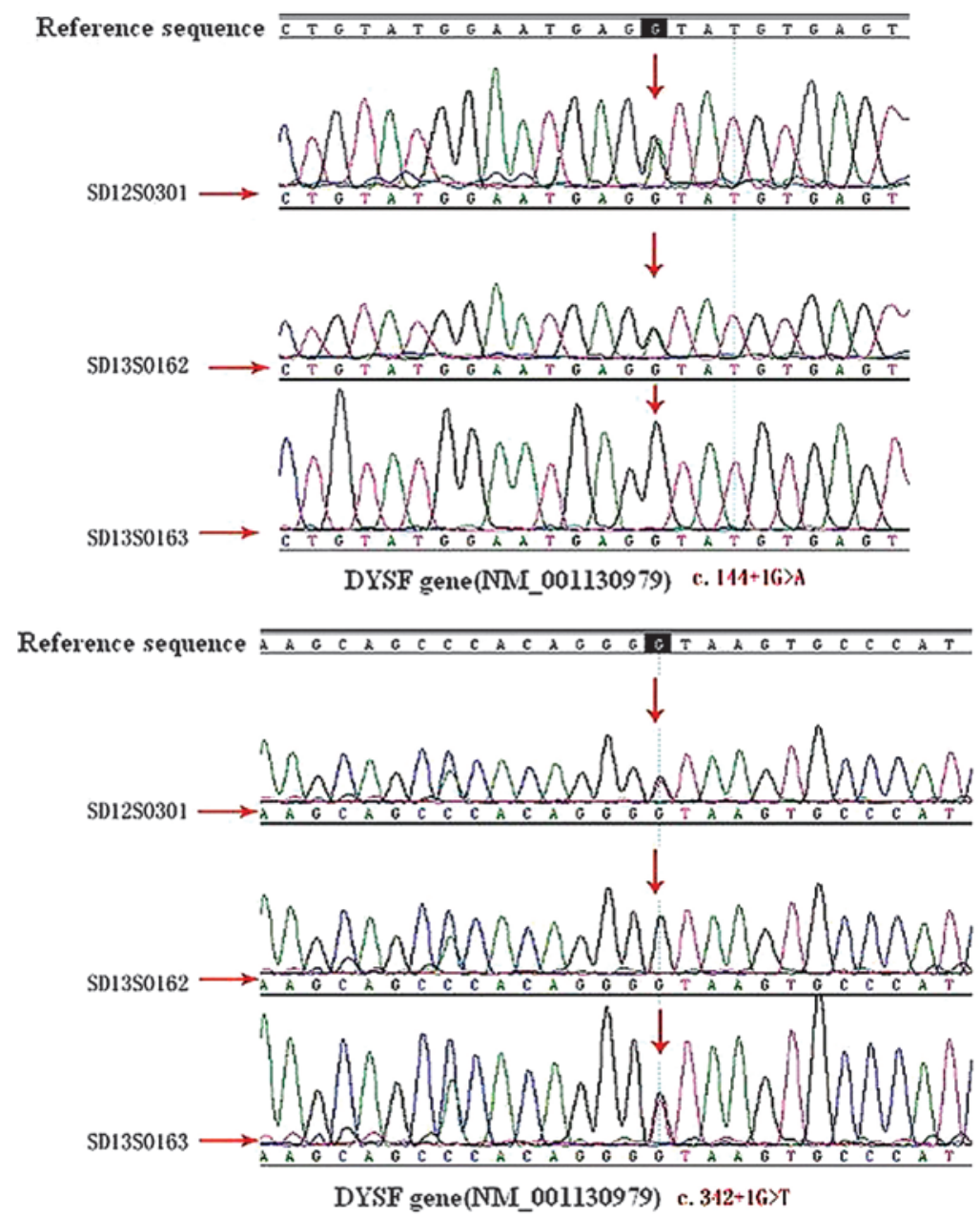

Figure 2. Sequence maps of the patient and the patient's mother and sister by exon trapping and sequence analysis. SD13S0301, patient; SD13S0162. patient's sister; SD13S0163, patient's mother. DYST, dysferlin. 
translation from the 115th amino acid. Thus, abnormal expression levels of the DYSF protein were observed. The patient's mother and sister carried different splice site mutations, and the patient's father was suspected to carry the same splice site mutations as the patient's sister. The patient had two splice site mutations, one inherited from each parent, which led to the abnormal expression of the DYSF gene, resulting in LGMD2B. LGMD2B displays autosomal recessive inheritance. As the patient's wife is not a carrier of the gene, prenatal diagnosis of the fetus was not recommended following genetic counseling.

The characteristic features of LGMD2B are late onset, with no typical initial symptoms and slow progression (18). Furthermore, numerous other genes are also associated with myogenic damage. Therefore, a definitive diagnosis of LGMD2B is complex. Types of LGMD include LGMD2A, LGMD2B, LGMD2G, LGMD2H, LGMD2I, LGMD2J, LGMD2C, LGMD2D, LGMD2E, and LGMD2F, of which the first six are known as 'light type', and the latter four as 'heavy type' (19). Pathogenic genes are associated with coding sarcoglycan, and each type was accompanied with the mutation of associated genes (20). With significant genetic heterogeneity, various clinical symptoms and the complexity of classification, the diagnosis of LGMD is difficult (21). In addition, several aspects of the pathogenesis have yet to be elucidated, and excluding the mutations of possible genes one at a time is also a convoluted process. In the present study, 399 genes were captured for targeted microarray and detected by next-generation sequencing technology and exon capture and sequence analysis simultaneously. Suspicious mutations were screened and any polymorphisms were excluded. The results were verified by the Sanger method. The diagnosis may also be made in the absence of a muscle biopsy and immunohistochemical examination. Exon capture and sequence analysis greatly improved the efficiency of diagnosis, and is an efficient and accurate method for clinical and differential diagnosis.

In conclusion, exon capture high-throughput sequencing is able to simultaneously sequence hundreds of genes, significantly reducing the time required for clinical and differential diagnosis, in particular, for cases of disease caused by inconclusive or equivocal genes. However, it may have limited application in the clinical diagnosis of disease in which the genes involved are clear, due to the high costs of the procedure.

\section{Acknowledgements}

All data and experiments were performed by the authors of the present study. The authors are grateful to Professor Xiao ming Wei (BGI-Wuhan, Wuhan, China) for technical support and assistance in the experimental process. This investigation received no specific grant from any funding agency in the public, commercial or not-for-profit sectors.

\section{References}

1. Bansal D, Miyake K and Vogel SS, Groh S, Chen CC, Williamson R, McNeil PL and Campbell KP: Defective membrane repair in dysferlin-deficient muscular dystrophy. Nature 423: 168-172, 2003

2. Fuson K, Rice A, Mahling R, Snow A, Nayak K, Shanbhogue P, Meyer AG, Redpath GM, Hinderliter A, Cooper ST and Sutton RB: Alternate splicing of dysferlin $\mathrm{C} 2 \mathrm{~A}$ confers $\mathrm{Ca}^{+}$-dependent and $\mathrm{Ca} 2^{+}$-independent binding for membrane repair. Structure 22: $104-115,2014$.
3. Lek A, Evesson FJ, Lemckert FA, Redpath GM, Lueders AK, Turnbull L, Whitchurch CB, North KN and Cooper ST: Calpains, cleaved mini-dysferlinC72, and L-type channels underpin calcium-dependent muscle membrane repair. J Neurosci 33: 5085-5094, 2013.

4. Guglieri M, Magri F, D'Angelo MG, Prelle A, Morandi L, Rodolico C, Cagliani R, Mora M, Fortunato F, Bordoni A, et al: Clinical, molecular, and protein correlations in a large sample of genetically diagnosed Italian limb girdle muscular dystrophy patients. Hum Mutat 29: 258-266, 2008.

5. Guglieri M, Straub V, Bushby K and Lochmüller H: Limb-girdle muscular dystrophies. Curr Opin Neurol 21: 576-584, 2008.

6. Wenz T, Diaz F, Hernandez D and Moraes CT: Endurance exercise is protective for mice with mitochondrial myopathy.J Appl Physiol 1985 106: 1712-1719, 2009.

7. Angelini C, Nardetto L, Borsato C, Padoan R, Fanin M, Nascimbeni AC and Tasca E: The clinical course of calpainopathy (LGMD2A) and dysferlinopathy (LGMD2B).Neurol Res 32: 41-46, 2010.

8. Bashir R, Strachan T Keers S, Stephenson A, Mahjneh I, Marconi G, Nashef L and Bushby KM: A gene for autosomal recessive limb-girdle muscular dystrophy maps to chromosome 2p. Hum Mol Genet 3: 455-457, 1994.

9. Matsuda C, Hayashi YK, Ogawa M, Aoki M, Murayama K, Nishino I, Nonaka I, Arahata K and Brown RH Jr: The sarcolemmal proteins dysferlin and caveolin-3 interact in skeletal muscle. Hum Mol Genet 10: 1761-1766, 2001.

10. Passos-Bueno MR, Richard I, Vainzof M, Fougerousse F, Weissenbach J, Broux O, Cohen D, Akiyama J, Marie SK and Carvalho AA: Evidence of genetic heterogeneity in the autosomal recessive adult forms of limb-girdle muscular dystrophy following linkage analysis with $15 \mathrm{q}$ probes in Brazilian families. J Med Genet 30: 385-387, 1993.

11. Cagliani R, Fortunato F, Giorda R, Rodolico C, Bonaglia MC, Sironi M, D'Angelo MG, Prelle A, Locatelli F, Toscano A, et al: Molecular analysis of LGMD-2B and MM patients: Identification of novel DYSF mutations and possible founder effect in the Italian population. Neuromuscul Disord 13: 788-795, 2003.

12. Bashir R, Britton S, Strachan T, Keers S, Vafiadaki E, Lako M, Richard I, Marchand S, Bourg N, Argov Z, et al: A gene related to Caenorhabditis elegans spermatogenesis factor fer-1 is mutated in limb-girdle muscular dystrophy type 2B. Nat Genet 20: 37-42, 1998.

13. Kerr JP, Ziman AP, Mueller AL, Muriel JM, Kleinhans-Welte E, Gumerson JD, Vogel SS, Ward CW, Roche JA and Bloch RJ: Dysferlin stabilizes stress-induced $\mathrm{Ca} 2+$ signaling in the transverse tubule membrane. Proc Natl Acad Sci USA 110: 20831-20836, 2013.

14. Passos-Bueno MR, Bashir R, Moreira ES, Vainzof M, Marie SK, Vasquez L, Iughetti P,Bakker E, Keers S, Stephenson A: Confirmation of the $2 \mathrm{p}$ locus for the mild autosomal recessive limb-girdle muscular dystrophy gene (LGMD2B) in three families allows refinement of the candidate region. Genomics 27: 192-195, 1995.

15. Bashir R, Keers S, Strachan T, Passos-Bueno R, Zatz M, Weissenbach J, Le Paslier D, Meisler M and Bushby K: Genetic and physical mapping at the limb-girdle muscular dystrophy locus (LGMD2B) on chromosome 2p. Genomics 33: 46-52, 1996.

16. Wenzel K, Carl M, Perrot A, Zabojszcza J, Assadi M, Ebeling M, Geier C, Robinson PN, Kress W, Osterziel KJ and Spuler S: Novel sequence variants in dysferlin-deficient muscular dystrophy leading to mRNA decay and possible C2-domain misfolding. Hum Mutat 27: 599-600, 2006.

17. Krahn M, Béroud C, Labelle V, Nguyen K, Bernard R, Bassez G, Figarella-Branger D, Fernandez C, Bouvenot J, Richard I, et al: Analysis of the DYSF mutational spectrum in a large cohort of patients. Hum Mutat 30: E345-E375, 2009.

18. Nguyen K, Bassez G, Bernard R, Krahn M, Labelle V, Figarella-Branger D, Pouget $\mathrm{J}$, Hammouda $\mathrm{H}$, Béroud $\mathrm{C}$, Urtizberea A, et al: Dysferlin mutations in LGMD2B, Miyoshi myopathy, and atypical dysferlinopathies. Hum Mutat 26: 165, 2005.

19. Kong KY, Ren J, Kraus M, Finklestein SP and Brown RH Jr: Human umbilical cord blood cells differentiate into muscle in sjl muscular dystrophy mice. Stem Cells 22: 981-993, 2004.

20. Urtasun M, Poza JJ, Gallano P, Lasa A, Sáenz A, Cobo AM, Leturcq F, López de Munain A and García-Bragado F: Muscular dystrophy due to a mutation in the gene of alpha-sarcoglycan subunit of dystrophin associated protein complex. Med Clin 110: 538-542, 1998. (In Spanish)

21. Vainzof M, Anderson LV, McNally EM, Davis DB, Faulkner G, Valle G, Moreira ES, Pavanello RC, Passos-Bueno MR and Zatz M: Dysferlin protein analysis in limb-girdle muscular dystrophies. J Mol Neuorsci 17: 71-80, 2001. 